\title{
Parental risk factors for the development of pediatric acute and chronic postsurgical pain: a longitudinal study
}

This article was published in the following Dove Press journal:

Journal of Pain Research

27 September 2013

Number of times this article has been viewed

\section{Gabrielle Pagé \\ Fiona Campbell ${ }^{2,3}$ \\ Lisa Isaac ${ }^{2,3}$ \\ Jennifer Stinson ${ }^{2,4}$ \\ Joel Katz'1,3,5}

'Department of Psychology, Faculty of Health, York University, Toronto, ON, Canada; ${ }^{2}$ Department of Anesthesia and Pain Medicine, Hospital for Sick Children, Toronto, ON, Canada; ${ }^{3}$ Department of Anesthesia, Faculty of Medicine, University of Toronto, Toronto, ON, Canada; ${ }^{4}$ Lawrence $S$ Bloomberg Faculty of Nursing, University of Toronto, Toronto, ON, Canada; ${ }^{5}$ Department of Psychology, Hospital for Sick Children, Toronto, ON, Canada
Correspondence: Joel Katz Department of Psychology, Faculty of Health, BSB 232, York University, 4700 Keele Street, Toronto, ON M3J IP3, Canada

Tel +l 4167362100 ext 40557

Email jkatz@yorku.ca
Background: The goal of this longitudinal study was to examine the associations among psychological factors and pain reports of children and their parents over the 12 month period after pediatric surgery.

Materials and methods: Included in the study were 83 children aged 8-18 years undergoing major surgery. In each case, the child and one of their parents completed measures of pain intensity and unpleasantness, psychological function, and functional disability at 48-72 hours, 2 weeks (child only), 6 months, and 12 months after surgery.

Results: The strength of the correlation coefficients between the psychological measures of the parent and their child increased significantly over time. There was a fair level of agreement between parent ratings of child acute and chronic pain ( 6 months after surgery) and the child's actual ratings. Parent and child pain anxiety scores 48-72 hours after surgery interacted significantly to predict pain intensity, pain unpleasantness, and functional disability levels 2 weeks after discharge from hospital. Parent pain catastrophizing scores 48-72 hours after surgery predicted child pain intensity reports 12 months later.

Conclusion: These results raise the possibility that as time from surgery increases, parents exert greater and greater influence over the pain response of their children, so that by 12 months postsurgery mark, parent pain catastrophizing (measured in the days after surgery) is the main risk factor for the development of postsurgical pain chronicity.

Keywords: pain anxiety, pain catastrophizing, children, parental risk factors, postsurgical pain

\section{Introduction}

Research on the role of psychological and social factors in pain perception has increased exponentially since the publication of the Gate Control Theory ${ }^{1}$ and biopsychosocial models of pain. ${ }^{2,3}$ Recently, factors relevant to pain perception have become central components of several pain models including the integrative model of parent and family factors in pediatric chronic pain and associated disability ${ }^{4}$ and the pediatric fearavoidance model of chronic pain. ${ }^{5}$ The former model $^{4}$ proposes that three interrelated levels of factors influence pediatric pain and disability: (1) individual factors (eg, parent behaviors such as solicitousness, parent reinforcement, parenting style), (2) parentchild interactions, and (3) family-related variables (eg, familial environment). In addition, several mediators and/or moderators of the relationships between pain, disability, and the three interrelated levels of factors mentioned above are proposed (eg, sex, age, developmental stage, coping, family history, and emotional symptoms). The latter model ${ }^{5}$ recognizes the bidirectional relationship between parent and child factors as contributing to the initiation and maintenance of the pain experience. The ways in which 
parents react to their children's pain (including protective and solicitous behaviors and parents' psychological responses) also influence their children's behaviors and psychological responses to pain.

As highlighted in the pediatric fear-avoidance model of chronic pain ${ }^{5}$, children's thoughts and beliefs related to the pain experience are shaped over time initially through interaction with their parents. ${ }^{4,6}$ Moreover, pain experiences affect one's empathic responses to the pain of others, ${ }^{7,8}$ and this is particularly true of the parent-child relationship. ${ }^{7}$ Based on prior pain experiences and current beliefs and thoughts about pain, a parent might interpret his/her child's pain as threatening. This interpretation will likely lead to a higher estimation of the child's pain and an increased level of parental distress; ${ }^{9-11}$ these factors will in turn affect the child's pain behaviors and expressions ${ }^{12-14}$ and pain-related functional disability. ${ }^{9,10,15}$

Understanding the transition from acute to chronic postsurgical pain (CPSP) in children would be enhanced by addressing these critically important parental influences on children's pain experiences. Research has shown that (1) parents are affected by their child's experience of a long-term condition or hospitalization; ${ }^{16,17}$ (2) parents of hospitalized children report feelings of anxiety, fear, guilt, a sense of lack of control, and distress; ${ }^{18}$ (3) high levels of parent anxiety prior to their child's surgery are associated with higher levels of child anxiety, ${ }^{19}$ and parent postoperative anxiety correlates strongly with child postoperative anxiety; ${ }^{20}$ (4) some parental behaviors intended to reduce a child's pain, such as reassurance, have been shown to increase the child's distress level, ${ }^{21}$ and (5) parent distraction is associated with fewer child activity restrictions, whereas parent protective behaviors are associated with more child activity restrictions among children with juvenile idiopathic arthritis. ${ }^{22}$

Taken together, these studies show that parents are significantly affected by their children's pain experience; at the same time, parents also influence their children's response to pain. Nevertheless, it remains unclear how parent and child pain-related psychological variables and pain reports are related and how/whether this relationship evolves over time as acute postoperative pain becomes chronic.

The objectives of this study were to (1) examine the correlations among child and parent pain-related psychological factors as well as the agreement between child and parent pain reports over the 12 months after pediatric surgery, (2) identify parent pain-related psychological risk factors associated with child acute postsurgical pain 48-72 hours after surgery, and (3) identify parent pain-related psychological risk factors that predict pediatric CPSP 6 months and 12 months after surgery. Within the context of this study, CPSP is defined as the presence of pain of a moderate to severe intensity (average pain score of $\geq 4$ or higher out of 10 on the numeric rating scale [NRS]) 6 months and/or 12 months after surgery. ${ }^{23}$ Children who reported experiencing no pain or mild pain (pain intensity score of $\leq 3$ on the NRS) were classified into the no/mild CPSP group.

Child and parent pain-related psychological constructs examined in this study include pain anxiety, pain catastrophizing, and anxiety sensitivity. Pain anxiety refers to cognitive, physiological, behavioral, and fear dimensions of anxiety that are associated with current or anticipated pain experience. ${ }^{24,25}$ Pain catastrophizing refers to cognitive and fear (rumination, helplessness, magnification) responses associated with actual or anticipated pain experience. ${ }^{26}$ Anxiety sensitivity refers to the fearful interpretation of anxiety symptoms due to the belief that they might lead to potentially harmful or negative consequences. ${ }^{27}$ Recent studies have shown that although these constructs are related, there is evidence that they contribute uniquely to the explanation of chronic pain disability after adult surgery. ${ }^{28}$

These constructs were selected because they have been shown to be associated with child and adolescent pain severity and pain-related disability, ${ }^{29-31}$ and they are central components of empirically validated models of chronic pain such as the diathesis-stress model of chronic pain and disability $^{32,33}$ and the cognitive-behavioral fear-avoidance model of chronic pain. ${ }^{34,35}$

\section{Materials and methods Participants and recruitment}

Children between the ages of 8-18 years who underwent either general surgical (thoracotomy, thoracoabdominal surgery, Nuss/Ravitch procedure, sternotomy, laparotomy, ostomy) or orthopedic (scoliosis, osteotomy, plate insertion tibia/femur, open hip reduction, hip capsulorrhaphy) procedures and one of their parents were eligible to participate in this study. Exclusion criteria included developmental or cognitive delay, being nonverbal, having cancer, or having a congenital insensitivity to pain. Inclusion criteria, other than age and surgery type, included both child and parent being fluent in written and spoken English.

\section{Questionnaires}

\section{Child measures}

The Child Pain Anxiety Symptoms Scale (CPASS) ${ }^{36}$ is a 20-item, self-report, scale for children, adapted from the 
adult PASS-20. ${ }^{37}$ Children rate the extent to which they think, act, or feel in relation to each item on a scale from 0 ("never think, act, or feel that way") to 5 ("always think, act, or feel that way"). Total score ranges from 0-100, with higher scores indicating higher levels of pain anxiety. The CPASS consists of four subscales: cognitive, escape/avoidance, fear, and physiological anxiety. The CPASS showed excellent internal consistency $(\alpha=0.90)$ in a community sample of children $^{36}$ as well as in the present sample $(\alpha=0.92-0.96) .{ }^{38}$ The construct and discriminative validity of the CPASS are adequate as evidenced by greater correlations between the CPASS and pain catastrophizing $(r=0.63)$ and anxiety sensitivity $(r=0.60)$ than with general anxiety $(r=0.44)$. The CPASS was significantly associated with the frequency of pain reports in children. ${ }^{36}$

The Childhood Anxiety Sensitivity Index $(\mathrm{CASI})^{39}$ is an 18-item scale that measures the extent to which participants interpret anxiety-related symptoms (eg, increased heart rate, feeling nauseated) as indicators of potentially harmful somatic, psychological, and/or social consequences. ${ }^{40}$ Each item on the CASI is rated on a four-point Likert scale ranging from 1 ("none") to 3 ("a lot") yielding total scores between 18 and 54, with higher scores indicating higher levels of anxiety sensitivity. The CASI has good internal consistency ( $\alpha=0.87)$, test-retest reliability ( $r=0.76)$, as well as adequate convergent and discriminant validity. ${ }^{39}$ Internal consistency for the present study was excellent ( $\alpha=0.87-0.93)$.

The Pain Catastrophizing Scale - Children (PCS-C) ${ }^{26}$ measures the extent to which children worry, amplify, and feel helpless about their current or anticipated pain experience. ${ }^{26}$ The 13 -item PCS-C is a modification of the adult PCS. ${ }^{41,42}$ Children rate each item on a scale from 0 ("not at all") to 4 ("extremely"), "how strongly they experience this thought" when they have pain. Total scores range from 0-52, with higher scores indicating higher levels of pain catastrophizing. The PCS-C also yields three subscale scores, namely rumination, magnification, and helplessness. The PCS-C has good internal consistency $(\alpha=0.90)$ and correlates highly with pain intensity $(r=0.49)$ and disability $(r=0.50) .{ }^{26}$ Internal consistency for the present study was excellent $(\alpha=0.93)$.

Functional Disability Inventory (FDI-C $)^{43}$ is a self-report measure that assesses the extent to which children experience difficulties in completing specific tasks of daily living. Typically, the FDI-C is used as a five-point Likert scale and yields total scores ranging from 0-60. Inadvertently, the FDI-C in the present study was measured using a four-point
Likert scale and omitted the original "2" ("some trouble"). Children in this study rated each of the 15 items on a scale from 0-3: (0: "no trouble"; 1: "a little trouble", 2: "a lot of trouble", and 3: "impossible"). Total scores range from 0-45 with higher scores indicating higher levels of disability. The FDI-C has excellent internal consistency $(\alpha=0.86-0.91)$ and good test-retest reliability at 2 weeks $(r=0.74)$ and 3 months $(r=0.48)$. The FDI-C has been used with many pediatric populations including children with chronic pain ${ }^{44-46}$ and postsurgical pain. ${ }^{47}$ Internal consistency for the present study was excellent ( $\alpha=0.83-0.89)$.

The 11-point NRS for Pain Intensity (NRSI) and Pain Unpleasantness (NRSU) are verbally administered 11-point scales that measures pain intensity ("how much pain do you feel right now?"). The NRS was also used to measure pain unpleasantness ("how unpleasant/horrible/yucky is the pain right now?"). The end points represent the extremes of the pain experience. Since there are no agreed upon NRS anchors for measuring pain in children and adolescents, ${ }^{48}$ the following anchors were used in the present study: for pain intensity, $0=$ "no pain at all" to $10=$ "worst possible pain"; for pain unpleasantness, $0=$ "not at all unpleasant/horrible/yucky" to $10=$ "most unpleasant/horrible/yucky feeling possible." The NRSI has been validated as an acute postoperative pain measure in children aged 7-17 years ${ }^{38}$ and correlates highly with the Visual Analog Scale $(r=0.89)$ and the Faces Pain Scale-revised $(r=0.87) .{ }^{49}$

To determine preoperative pain, children were asked retrospectively (48-72 hours after surgery) how much pain they had had on average before the surgery using a four-point verbal rating scale $(0=$ "no pain"; 1 = "a little bit of pain"; 2 = "a moderate amount of pain"; 3 = "a lot of pain"). Only three children with preoperative pain reported pain at the 6-month or 12-month follow-up; for the remaining 18, the surgery corrected the source of their pain. ${ }^{23}$

The CPSP Questionnaire-Child report was designed specifically for the present study to evaluate children's pain experience postoperatively. Children were asked questions about the presence/absence of pain ("Do you ever feel pain in the area of your body where the surgery was done?"), pain frequency ("How often do you feel pain?"), pain intensity and unpleasantness (11-point NRS), type of pain ("What kind of pain do you usually feel?"), pain location ("When you feel pain where exactly is the pain you are usually feeling?"), as well as pain management strategies utilized (eg, pain medication, doctor visits, physiotherapy). CPSP was defined based on the child's response to the question “On average, how much pain do you usually feel?" Children 
who rated their average pain as $\geq 4$ out of 10 were classified as having moderate/severe CPSP, and children who rated their average pain as $\leq 3$ out of 10 were classified as having no/mild CPSP.

\section{Parent measures}

The Pain Anxiety Symptoms Scale (PASS-20) ${ }^{37}$ is a short version of the PASS, ${ }^{25}$ consisting of 20 items assessing fear and anxiety reactions to pain. The four, five-item subscales of the PASS-20 measure cognitive anxiety, escape and avoidance responses, fearful thinking, and physiological anxiety responses. Participants answer each item on a scale from 0 ("never") to 5 ("always"). Total scores range from 0-100, higher score indicating higher level of pain anxiety. The scale has a good internal consistency ( $\alpha=0.81)$, good convergent validity with the original PASS-40 ( $r=0.95)$, and good construct validity. ${ }^{37}$ Reliability coefficients for the subscales range from $0.23-0.93$. Internal consistency for the present study was excellent ( $\alpha=0.938-0.959)$.

The Pain Catastrophizing Scale (PCS) ${ }^{41}$ is a 13-item self-report measure of pain catastrophizing that includes three subscales: rumination, magnification, and helplessness. Participants rate each item on a scale from 0 ("not at all") to 4 ("all the time"), for a total score of 52. Cronbach's $\alpha$ of 0.87 for the total scale is satisfactory. The scale also has good convergent validity with measures of anxiety $(r=0.32)$ and negative affect $(r=0.32)$. The 10 -week test-retest showed good reliability $(r=0.70)$. Internal consistency for the present study was excellent ( $\alpha=0.934-0.961)$.

The Anxiety Sensitivity Index (ASI) ${ }^{27}$ is a 16-item selfreport measure assessing the extent to which participants fear the potentially negative consequences of symptoms and sensations related to anxiety. Each item is rated on a scale from 0 ("very little") to 4 ("very much"), for a total score ranging from $0-64$. The ASI has a high total score internal consistency ( $\alpha=0.83)$ and has good convergent and discriminant validity. ${ }^{50}$ Internal consistency for the present study was excellent ( $\alpha=0.884-0.920)$.

The Postoperative Pain Measure for Parents (PPMP $)^{51}$ is a 15-item checklist that assesses behavior children exhibit in response to postoperative pain. For each item, parents select "yes" or "no" as to whether the child exhibits the behavior. The checklist has good internal consistency $(\alpha=0.88)$ and correlates highly with child ratings of pain $(r=0.61) .{ }^{51}$ Using a cut-off score of 6, the PPMP has been shown to be highly sensitive $(<80 \%)$ and specific $(>80 \%)$ in identifying children with clinically significant pain intensity 2 days after surgery. ${ }^{51}$ Internal consistency for the present study was adequate $(\alpha=0.756)$.

The Functional Disability Inventory - Parent report $(\text { FDI-P })^{43}$ is a 15 -item scale that assesses the extent to which children experience difficulties in completing specific tasks (eg, "walking to the bathroom", "eating regular meals", and "being at school all day"). Parents are asked to rate the extent to which their child experiences difficulties in completing each of the 15 items. Typically, the FDI-P is used as a five-point Likert Scale and yields total scores ranging from 0-60. Inadvertently, the FDI-P in this study was measured using a four-point Likert scale. Parents rated each item on a scale from 0 ("no trouble") to 3 ("impossible"), yielding total scores ranging from $0-45$. Internal consistency for the present study was adequate $(\alpha=0.798-0.886)$.

The CPSP Questionnaire - Parent report was designed specifically for this study to evaluate parent perception of child's pain experience postoperatively. Parents were asked questions about their children's pain experience, including the presence/ absence of pain ("Does your child ever feel pain in the area of his/her body where the surgery was done?"), pain frequency (“How often does your child feel pain?"), pain intensity and unpleasantness using the NRS ("On average, how much pain does your child feel on a scale from 0 to 10 ?"), type ("What kind of pain does your child usually feel?"), and location ("When your child feels pain where exactly is the pain she/he is usually feeling?") of pain, as well as pain management strategies utilized (eg, pain medication, doctor visits, physiotherapy).

\section{Procedure}

The study was reviewed and approved by the Research Ethics Boards of the Hospital for Sick Children and York University. Potential participants were initially approached approximately 48-72 hours after surgery by nurses not part of the research project. After expressing initial interest in the study to the nurse, children and one of their parents were then approached 48-72 hours after surgery by one of the research team members. After obtaining written parental consent and child consent or assent, questionnaires were verbally administered to children by one of the research team members (Table 1). Meanwhile, parents independently completed a similar set of questionnaires. The order of administration of questionnaires was randomized (http://www.randomization.com) within participants to minimize potential order and fatigue effects. Telephone follow-up calls were conducted approximately 2 weeks after discharge from hospital (children only) and 6 months and 12 months after surgery with both parents and children (Table 1). This manuscript is part of a 
Table I Questionnaires and their timing of administration to children and parents

\begin{tabular}{|c|c|c|c|c|c|}
\hline Participant & Measures & 48-72 hours & 2 weeks & 6 months & 12 months \\
\hline \multirow[t]{9}{*}{ Child } & Demographics & $\checkmark$ & & & \\
\hline & CPASS & $\checkmark$ & $\checkmark$ & $\checkmark$ & $\checkmark$ \\
\hline & PCS-C & $\checkmark$ & & $\checkmark$ & $\checkmark$ \\
\hline & CASI & $\checkmark$ & & $\checkmark$ & $\checkmark$ \\
\hline & NRSI & $\checkmark$ & $\checkmark$ & $\checkmark$ & $\checkmark$ \\
\hline & NRSU & $\checkmark$ & $\checkmark$ & $\checkmark$ & $\checkmark$ \\
\hline & FDI-C & & $\checkmark$ & $\checkmark$ & $\checkmark$ \\
\hline & CPSP & & & $\checkmark$ & $\checkmark$ \\
\hline & Questionnaire-C & & & & \\
\hline \multirow[t]{8}{*}{ Parent } & Demographics & $\checkmark$ & & & \\
\hline & PASS-20 & $\checkmark$ & & $\checkmark$ & $\checkmark$ \\
\hline & PCS & $\checkmark$ & & $\checkmark$ & $\checkmark$ \\
\hline & ASI & $\checkmark$ & & $\checkmark$ & $\checkmark$ \\
\hline & PPMP & $\checkmark$ & & & \\
\hline & FDI-P & & & $\checkmark$ & $\checkmark$ \\
\hline & CPSP & & & $\checkmark$ & $\checkmark$ \\
\hline & Questionnaire-P & & & & \\
\hline
\end{tabular}

Abbreviations: ASI, Anxiety Sensitivity Index; CASI, Childhood Anxiety Sensitivity Index; CPASS, Child Pain Anxiety Symptoms Scale; CPSP Questionnaire-C, Chronic Postsurgical Pain Questionnaire - Child report; CPSP Questionnaire-P, Chronic Postsurgical Pain Questionnaire - Parent report; FDI-C, Functional Disability Inventory Child report; FDI-P, Functional Disability Index - Parent report; NRSI, Numerical Rating Scale for Pain Intensity; NRSU, Numerical Rating Scale for Pain Unpleasantness; PASS-20, Pain Anxiety Symptoms Scale-20; PCS, Pain Catastrophizing Scale; PCS-C, Pain Catastrophizing Scale - Children; PPMP, Postoperative Pain Measure for Parents.

larger project examining validation of pain anxiety and predictors of acute and chronic postoperative pain in children. ${ }^{23,38,52}$

\section{Data analysis}

Data were screened for the presence of univariate outliers on pain-related psychological predictor variables (pain anxiety, pain catastrophizing, and anxiety sensitivity), multivariate outliers (squared Mahalanobis distance has a probability $\chi^{2}<0.001$ ), as well as skewness and kurtosis for both child and parent measures.

Outlier analysis revealed that none of the data points was both a univariate and a multivariate outlier; as such, all participants were retained for the analyses. Skewness and kurtosis significance testing (estimate/standard error $>3$ ) revealed nonnormality of two outcome variables; namely, pain intensity and pain unpleasantness 2 weeks, 6 months, and 12 months after surgery. Nonnormality of the outcome variables was addressed through square root transformation (NRSI[2] $]^{t}, \mathrm{NRSU}[2]^{\mathrm{t}}, \mathrm{NRSI}[6]^{\mathrm{t}}, \mathrm{NRSU}[6]^{\mathrm{t}}, \mathrm{NRSI}[12]^{\mathrm{t}}$, and NRSU[12] $]^{t}$, which resulted in normally distributed variables (skewness and kurtosis significance testing estimate/ standard error $<3$ ). The superscript symbol " $t$ " following a variable name indicates that this variable has been transformed to address nonnormality. Neither child nor parent pain-related psychological predictors were found to be skewed or kurtotic.

\section{Correlation and concordance between child and parent pain-related psychological factors and pain reports Correlations between child and parent pain-related psychological factors}

The associations among parent (PASS, PCS, ASI) and child (CPASS, PCS-C, CASI) pain-related psychological measures were examined using Pearson correlation coefficients. Strength of correlations between measures was examined using $R^{2}$ and $90 \%$ confidence intervals.

\section{Agreement/relationship between child and parent ratings of a child's pain}

To determine a relationship between child and parent acute postsurgical pain ratings, two-tailed, Bonferroni-adjusted $(\alpha=0.025) t$-tests were used to examine differences in NRSI(0) scores and NRSU(0) scores using a cut-off score of 6 on the PPMP. We compared children whose parents rated them as having a score of $\geq 6$ on the $\operatorname{PPMP}^{51}$ (a clinically significant level of pain) with children whose parents rated them as having a score $<6$ on the PPMP (a nonclinically significant level of pain).

To determine agreement between child and parent CPSP ratings, inter-rater agreement between parental perception of the child's CPSP status (no/mild CPSP versus moderate/ severe CPSP) and child self-report of CPSP status was 
examined 6 months and 12 months after surgery using Cohen's kappa coefficient ${ }^{53}$ ( $\alpha$ set at 0.025 ). For both child report and parent report of the child's pain, moderate/severe CPSP was defined as the presence of pain of an intensity $\geq 4$ on the NRS 6 months and/or 12 months after surgery.

\section{Parent and child factors associated with pediatric acute postsurgical pain 2 weeks after hospital discharge}

A multivariate general linear model (multivariate multiple regression analysis) was fit to the data to examine the effect of parent and child pain-related psychological measures and their interactions on child acute pain and functional disability levels. The PASS $(0)$ and $\operatorname{CPASS}(0)$ and their interaction (using centered variables) as well as $\operatorname{PCS}(0)$ and $\mathrm{PCS}-\mathrm{C}(0)$ and their interaction (using centered variables) 48-72 hours after surgery were entered as predictors of child NRSI( 0$)$ and NRSU(0) (model 1) and NRSI(2) ${ }^{\mathrm{t}}, \mathrm{NRSU}(2)^{\mathrm{t}}$, and FDI-C(2) 2 weeks after discharge from hospital (model 2). $\alpha$ level was set at 0.025 to control for multiple comparisons. Significant multivariate effects were followed-up with univariate multiple regression analyses.

\section{Parent predictors of pediatric CPSP}

Stepwise linear regression analyses were conducted to examine parent predictors of child CPSP. The PASS $(0), \operatorname{PCS}(0)$, and $\operatorname{ASI}(0)$ measured 48-72 hours after surgery were entered as predictors of children's pain intensity 6 months $\left(\mathrm{NRSI}[6]^{\mathrm{t}}\right.$ [model 1]) and 12 months (NRSI[12 $]^{\mathrm{t}}[$ model 2]) after surgery ( $\alpha$ set at 0.025 ).

\section{Sample size analysis}

Sample size was estimated a priori (for all analyses except the multivariate multiple linear regression analyses) using $\mathrm{G}^{*}$ Power version 3.1 (Franz Faul, Universitat Kiel, Germany). ${ }^{54}$

\section{8-72 hours after surgery}

Sample size analysis showed that 64 participants would be required for a two-tailed point biserial correlation with $\alpha=0.05$, and a power of $80 \%$, and with a medium effect size.

\section{2 weeks after discharge from hospital}

Given that sample size analyses for multivariate multiple linear regression analyses are not readily accessible, power analyses were computed post hoc. Post hoc power analysis is important to rule out that nonsignificant findings are not due to lack of power. Power analysis for three response variables and six predictors showed that with 83 participants, noncentrality parameter $\lambda=16.6, \alpha=0.025$, numerator $d f=2$, denominator $d f=71$, and a power of $92.0 \%$. Power analysis for three response variables and six predictors showed that with 83 participants, noncentrality parameter $\lambda=16.6, \alpha=0.025$, numerator $d f=2$, denominator $d f=57$, and a power of $87.3 \%$.

\section{6 months and 12 months after surgery}

Sample size analysis showed that 57 participants would be required for a linear regression analysis with three predictors, $\alpha=0.025$, effect size $f^{2}=0.25$ and a power of $80 \%$.

Thus taking into account an attrition rate of $\sim 30 \%$ due to participant dropout and losing patients to follow-up, we recruited 83 patients to ensure we would have sufficient power for our analyses at the various time points after surgery.

\section{Results}

\section{Recruitment}

Children were recruited between July 2008 and September 2010. Details of the recruitment are presented in Figure 1. A total of 83 children participated in this study, of whom $69(83 \%), 61(73 \%)$, and $59(71 \%)$ completed the telephone follow-ups 2 weeks (mean $=15.6$ days, standard deviation [SD] $=2.15), 6$ months, and 12 months after discharge from the hospital, respectively.

\section{Descriptive statistics}

A total of 83 children (female $=56$ [67.5\%]) aged between $8-18$ years $($ mean $=13.8, \mathrm{SD}=2.4)$ and one of their parents (mothers $=63[75.9 \%]$; mean age $=44.0, \mathrm{SD}=6.6$ ) were used for the purpose of data analysis. The majority of children $(\mathrm{n}=53 ; 64 \%)$ and parents $(\mathrm{n}=56 ; 67.5 \%)$ in the sample self-identified as Caucasian. Eighty-nine percent of children spoke English as their first language at home, and $82 \%$ of parents identified English as the primary language spoken at home. Seventy-four percent of parents had completed at least some college/undergraduate education.

The majority of children underwent surgery for scoliosis (spinal fusion) $(n=42 ; 50.6 \%)$ or osteotomy $(n=25$; $30.1 \%)$; eight children $(9.6 \%)$ underwent Nuss $(n=5)$ or Ravitch $(\mathrm{n}=3)$ procedures, seven children $(8.4 \%)$ had a laparotomy, and one child had a thoracotomy. As described elsewhere, significant differences were not found in pain intensity or pain unpleasantness scores across the different surgical procedures while in hospital ${ }^{52}$ or after returning 


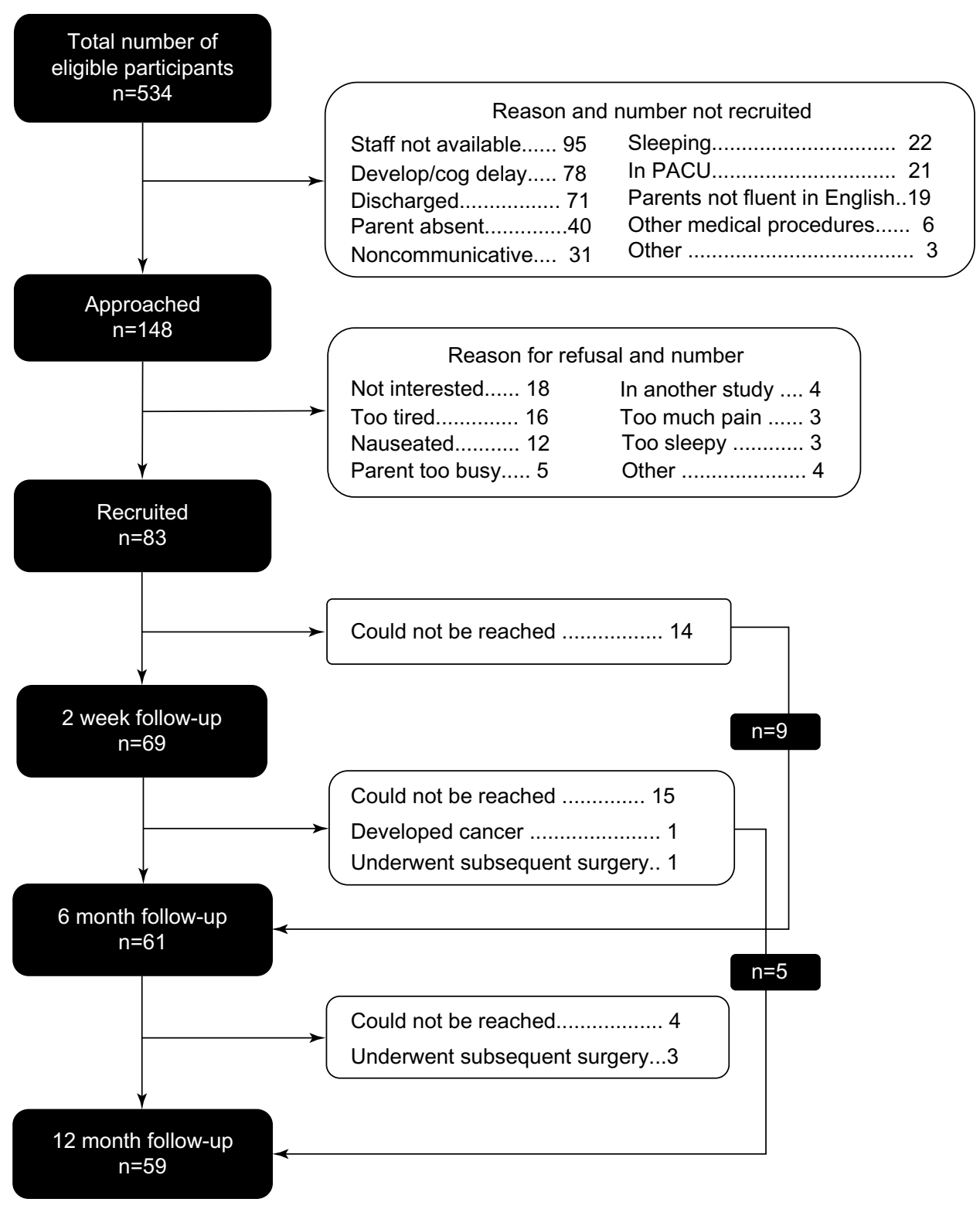

Figure I Flow chart describing recruitment process.

Abbreviations: Cog, cognitive; PACU, postanesthesia care; Develop, developmental.

home. ${ }^{23} \mathrm{~A}$ smaller proportion of boys than girls had surgery for scoliosis, and a greater proportion of boys had a Nuss or Ravitch procedure than expected by chance. ${ }^{52}$ This was the first surgery for 44 children (53\%); 39 others had previously undergone other surgical procedures (mean $=2.0, \mathrm{SD}=1.6$, range $=1-7)$. When asked to rate the level of presurgical pain they had experienced, the majority of children (80.7\%) reported "no pain" or "a little bit of pain." Approximately one quarter of parents reported having experienced chronic pain (either currently or in the past) $(n=20 ; 24.1 \%)$ whereas almost one third of parents reported experiencing ongoing pain problems $(\mathrm{n}=26 ; 31.7 \%)$.
Mean and SD of parent measures and medians and interquartile ranges of child pain experiences are presented in Tables 2 and 3, respectively.

\section{Correlation and concordance among child and parent pain-related psychological factors}

Correlations among child and parent pain-related psychological factors

Correlations among child and parent pain-related psychological measures are presented in Table 4. Significant correlation coefficients were found between child and parent 
Table 2 Means and standard deviations of parent pain-related psychological variables measured at 48-72 hours, 6 months, and 12 months after their child's surgery

\begin{tabular}{|c|c|c|c|c|c|c|c|c|c|}
\hline & \multicolumn{3}{|l|}{ Initial } & \multicolumn{3}{|c|}{6 months after surgery } & \multicolumn{3}{|c|}{ I 2 months after surgery } \\
\hline & $\begin{array}{l}\text { Fathers } \\
(n=20)\end{array}$ & $\begin{array}{l}\text { Mothers } \\
(n=63)\end{array}$ & $\begin{array}{l}\text { Total } \\
(n=83)\end{array}$ & $\begin{array}{l}\text { Fathers } \\
(n=I I)\end{array}$ & $\begin{array}{l}\text { Mothers } \\
(n=44)\end{array}$ & $\begin{array}{l}\text { Total } \\
(n=55)\end{array}$ & $\begin{array}{l}\text { Fathers } \\
(n=I I)\end{array}$ & $\begin{array}{l}\text { Mothers } \\
(n=39)\end{array}$ & $\begin{array}{l}\text { Total } \\
(n=50)\end{array}$ \\
\hline PASS & $25.45(16.9)$ & $29.06(19.2)$ & $28.19(18.6)$ & $35.27(20.7)$ & 31.91 (20.9) & $32.80(20.7)$ & $24.08(12.9)$ & $28.58(18.3)$ & $27.54(17.2)$ \\
\hline PCS & $11.55(6.9)$ & $14.16(11.0)$ & $13.5 \mid(10.1)$ & $19.91(12.4)$ & $14.45(12.7)$ & $15.58(12.7)$ & $15.17(10.1)$ & $13.70(10.0)$ & $14.04(9.9)$ \\
\hline ASI & $17.65(10.5)$ & $19.76(10.2)$ & $19.24(10.2)$ & $23.45(10.6)$ & $20.12(11.8)$ & 20.80 (II.6) & $19.25(11.3)$ & $19.13(12.2)$ & $19.15(11.9)$ \\
\hline FDI-P* & & & & $6.29(8.7)$ & $7.87(5.1)$ & $7.10(7.0)$ & $4.40(5.8)$ & $4.76(4.5)$ & $4.68(4.7)$ \\
\hline PPMP & $7.55(3.0)$ & $8.67(3.3)$ & $8.40(3.3)$ & & & & & & \\
\hline
\end{tabular}

Notes: When calculating a participant's total score on a questionnaire, mean imputation was used to replace missing items if the total number of missing items amounted to $\leq 5 \%$ of the questionnaire items. If $>5 \%$ of items on a specific questionnaire were left unanswered, total score for that participant was not calculated. *Functional disability scores were only computed for children who reported experiencing pain and do not take into account children who did not endorse pain at each time point. Functional Disability Index - Parent report was measured inadvertently on a scale from 0-3.

Abbreviations: ASI, Anxiety Sensitivity Index; FDI-P, Functional Disability Index - Parent report; PASS, Pain Anxiety Symptoms Scale-20; PCS, Pain Catastrophizing Scale; PPMP, Pain Measure for Parents.

pain catastrophizing 6 months and 12 months, but not 48-72 hours, after surgery. Using $R^{2}$ and $90 \%$ confidence intervals, the magnitude of the correlation coefficients between child and parent pain anxiety, pain catastrophizing, and anxiety sensitivity increased significantly from 48-72 hours to 12 months after surgery (Figure 2).

Agreement/relationship between child and parent ratings of their children's pain

Mean pain intensity and pain unpleasantness scores 48-72 hours after surgery were compared between children whose parents' ratings on the PPMP identified the children as having clinically significant (PPMP score $\geq 6$ ) ${ }^{51}$ or lower than clinically significant (PPMP score $<6$ ) levels of pain. Child self-reported pain intensity scores were significantly higher (mean NRSI $=4.08, \mathrm{SD}=2.3$ ) in the clinically significant parent grouping (PPMP score $\geq 6$ ) compared to the below clinically significant parent grouping (PPMP score $<6)(t[79]=2.37, P=0.020)($ mean NRSI $=2.63$, $\mathrm{SD}=1.9)$. Significant differences were not found for pain unpleasantness scores $(\mathrm{NRSU}=4.57, \mathrm{SD}=2.8$ and $\mathrm{NRSU}=4.31, \mathrm{SD}=2.8$ for the clinically significant and below clinically significant parent groupings, respectively) $(P=0.743)$.

Children and parents were asked whether or not the child experienced pain and if so, to rate the intensity of the pain using the NRSI, at 6 months and 12 months after surgery. This information was used to classify the ratings into moderate/severe CPSP (NRS $\geq 4$ ) and no/mild CPSP $(\mathrm{NRS}<3)$ at both 6 months and 12 months after surgery for both child report and parent report of the child's pain. Results indicate a fair agreement between child and parent ratings at 6 months $(\kappa=0.300, P<0.023)$ but not 12 months $(\kappa=0.175, P=0.205)$ after surgery (Table 5$)$.
These findings were not moderated by child or parent sex or child age.

\section{Parent pain-related psychological factors associated with pediatric acute postsurgical pain}

Multivariate multiple linear regression analysis showed an overall significant interaction effect between CPASS(0) and $\operatorname{PASS}(0)$ on child $\operatorname{NRSI}(2)^{t}, \operatorname{NRSU}(2)^{t}$, and FDI-C(2) scores 2 weeks after discharge from hospital (Pillai's trace $=0.157, F[3,57]=3.53, P=0.020)$ but not $48-72$ hours after surgery $(P=0.562)$. The interaction effect between $\operatorname{CPASS}(0)$ and $\operatorname{PASS}(0)$ scores significantly predicted child NRSI $(2)^{\mathrm{t}}(F[1,59]=5.90, P=0.018 ; B=0.001)$, $\operatorname{NRSU}(2)^{\mathrm{t}}(F[1,59]=9.05, P=0.004 ; B=0.001)$ and FDI-C(2) $(F[1,59]=5.79, P=0.019 ; B=0.006)$ scores (Figure 3$)$.

\section{Parent pain-related psychological predictors of pediatric CPSP}

Stepwise linear regression analyses showed that parent pain catastrophizing 48-74 hours after surgery (PCS[0]) significantly predicted child NRSI score 12 months $(F[1,56]=7.62$, adjusted $R^{2}=0.104, R^{2}$ change $=0.120, P=0.008, \beta$ PCS $=-0.346$, $P=0.008)$, but not 6 months, after surgery.

\section{Discussion}

The goals of this study were to examine (1) the relationships among child and parent pain-related psychological factors, (2) perioperative parent pain-related psychological risk factors for pediatric acute postsurgical pain, and (3) perioperative parent pain-related psychological risk factors for the development of pediatric CPSP 6 months and 12 months after surgery. 
Table 3 Frequency $(n)$ of child and parent self-report of pain and median pain intensity, pain unpleasantness and functional disability scores in children measured 48-72 hours after surgery, 2 weeks after discharge, and 6 months and 12 months after surgery

\begin{tabular}{|c|c|c|c|c|}
\hline & $\begin{array}{l}\text { 48-72 hours after } \\
\text { surgery }\end{array}$ & $\begin{array}{l}2 \text { weeks after } \\
\text { discharge }\end{array}$ & $\begin{array}{l}6 \text { months after } \\
\text { surgery }\end{array}$ & $\begin{array}{l}12 \text { months after } \\
\text { surgery }\end{array}$ \\
\hline \multicolumn{5}{|c|}{ Child ratings } \\
\hline \multicolumn{5}{|l|}{ Pain (n) } \\
\hline No or mild CPSP pain (NRSI < 4) & 43 & 51 & 47 & 46 \\
\hline \multirow{2}{*}{ Moderate/severe CPSP pain (NRSI $\geq 4$ ) } & 40 & 18 & 14 & 13 \\
\hline & Median (IQR) & Median (IQR) & Median (IQR) & Median (IQR) \\
\hline \multicolumn{5}{|l|}{ Pain intensity (NRSI) } \\
\hline No or mild pain $(\mathrm{NRSI}<4)$ & $3.0(2-5)$ & $1.0(0-2)$ & $0.0(0-2)$ & $0.0(0-2)$ \\
\hline Moderate/severe CPSP pain (NRSI $\geq 4)$ & $3.5(3-6)$ & $3.0(0-4)$ & $5.0(4-6)$ & $4(4-6)$ \\
\hline Total sample & $3.0(2-6)$ & $2.0(I-4)$ & $2.0(0-3)$ & $0.0(0-3)$ \\
\hline \multicolumn{5}{|l|}{ Pain unpleasantness (NRSU) } \\
\hline No or mild pain $(\mathrm{NRSI}<4)$ & $4.0(2-5)$ & $1.0(0-3)$ & $0.0(0-2)$ & $0.0(0-2)$ \\
\hline Moderate/severe CPSP pain (NRSI $\geq 4$ ) & $6.0(4-8)$ & $3.0(0-5)$ & $4.0(3-6)$ & $5(4-6)$ \\
\hline Total sample & $5.0(2-6)$ & $2.0(0-4)$ & $1.0(0-3)$ & $0.0(0-3)$ \\
\hline \multicolumn{5}{|l|}{ Functional disability (FDI) } \\
\hline No or mild pain $(N R S I<4)$ & & $19.0(13-24)$ & $6.0(2-8)$ & $1.5(0-4)$ \\
\hline Moderate/severe CPSP pain (NRSI $\geq 4)$ & & $24.0(|8-3|)$ & $6.5(2-11)$ & $6(4-9)$ \\
\hline \multirow[t]{2}{*}{ Total sample } & & $19.0(14-25)$ & $6.0(2-10)$ & $3.0(0-6)$ \\
\hline & & & $\begin{array}{l}6 \text { months after } \\
\text { surgery }\end{array}$ & $\begin{array}{l}12 \text { months } \\
\text { after surgery }\end{array}$ \\
\hline \multicolumn{5}{|c|}{ Parent ratings of child's pain } \\
\hline \multicolumn{5}{|l|}{ Pain $(n)$} \\
\hline No or mild pain $(\mathrm{NRSI}<4)$ & & & 40 & 35 \\
\hline \multirow[t]{2}{*}{ Moderate/severe pain (NRSI $\geq 4)$} & & & 15 & 15 \\
\hline & & & Median (IQR) & Median (IQR) \\
\hline \multicolumn{5}{|l|}{ Pain intensity (NRSI) } \\
\hline No or mild pain $(N R S I<4)$ & & & $0.0(0-3)$ & $0.0(0-4)$ \\
\hline Moderate/severe CPSP pain (NRSI $\geq 4)$ & & & $4.0(0-6)$ & $3.0(I-6)$ \\
\hline Total sample & & & $1.0(0-4)$ & $2.0(0-4)$ \\
\hline \multicolumn{5}{|l|}{ Pain unpleasantness (NRSU) } \\
\hline No or mild pain $(\mathrm{NRSI}<4)$ & & & $0.0(0-4)$ & $0.0(0-5)$ \\
\hline Moderate/severe CPSP pain (NRSI $\geq 4)$ & & & $4.0(0-7)$ & $4.0(0-5)$ \\
\hline Total sample & & & $1.0(0-4)$ & $2.0(0-5)$ \\
\hline \multicolumn{5}{|l|}{ Functional disability (FDI) } \\
\hline No or mild pain $(\mathrm{NRSI}<4)$ & & & $4.0(I-8)$ & $2.0(0-5)$ \\
\hline Moderate/severe CPSP pain (NRSI $\geq 4)$ & & & $6.0(2-16)$ & $3.5(2-6)$ \\
\hline Total sample & & & $5.0(I-8)$ & $3.0(0-5)$ \\
\hline
\end{tabular}

Abbreviations: CPSP, chronic postsurgical pain; FDI, Functional Disability Index; IQR, interquartile range; NRSI, Numerical Rating Scale for Pain Intensity; NRSU, Numerical Rating Scale for Pain Unpleasantness; SD, standard deviation.

\section{Correlation and agreement of child and parent pain-related psychological factors and pain reports}

Overall, the correlation coefficients were low between parent and child psychological and pain-related psychological measures across the first year after pediatric surgery. Of interest however, are the changes in the strength of the correlation coefficients between parent and child pain-related psychological measures over time. While the relationship between parent and child pain catastrophizing was the only one to reach statistical significance in the months following surgery, the relationships between pain anxiety and anxiety sensitivity also increased in strength over time. It is possible that child and parent pain-related anxiety and catastrophizing are normally correlated, but that this relationship is disrupted in the days after surgery and then normalizes by 12 months after surgery.

As noted above, the relationship between parent and child pain catastrophizing reached statistical significance at 6 months and 12 months after surgery. It has been suggested that pain catastrophizing can be both dispositional and situational $1^{55-58}$ and is learned through pain experience. 
Table 4 Pearson correlation coefficients among child and parent pain-related psychological variables across time

\begin{tabular}{|c|c|c|c|c|c|c|c|c|c|}
\hline \multirow{2}{*}{$\begin{array}{l}\text { Child } \rightarrow \\
\text { Parent }\end{array}$} & \multicolumn{3}{|c|}{ 48-72 hours } & \multicolumn{3}{|c|}{6 months } & \multicolumn{3}{|c|}{12 months } \\
\hline & CPASS & PCS-C & CASI & CPASS & PCS-C & CASI & CPASS & PCS-C & CASI \\
\hline \multicolumn{10}{|l|}{$48-72$ hours } \\
\hline PASS & 0.009 & 0.080 & 0.097 & 0.146 & $0.295 *$ & 0.134 & 0.238 & 0.221 & 0.253 \\
\hline PCS & 0.009 & 0.170 & 0.070 & 0.072 & $0.260 *$ & -0.025 & 0.067 & 0.247 & 0.162 \\
\hline ASI & -0.034 & 0.095 & 0.042 & 0.188 & 0.232 & 0.129 & $0.39 I^{* *}$ & $0.408^{* *}$ & $0.345 * *$ \\
\hline \multicolumn{10}{|l|}{6 months } \\
\hline PASS & 0.181 & 0.128 & 0.008 & 0.164 & $0.330 *$ & 0.054 & 0.153 & $0.377^{* *}$ & 0.161 \\
\hline PCS & 0.108 & 0.093 & -0.132 & 0.375 ** & 0.456 ** & 0.101 & 0.257 & $0.455^{* *}$ & 0.052 \\
\hline ASI & 0.137 & $0.287^{*}$ & -0.081 & 0.240 & $0.355^{* *}$ & 0.056 & 0.147 & $0.355^{*}$ & 0.196 \\
\hline \multicolumn{10}{|l|}{12 months } \\
\hline PASS & 0.209 & 0.162 & 0.102 & 0.220 & 0.218 & 0.109 & 0.247 & $0.323 *$ & 0.213 \\
\hline PCS & 0.152 & 0.161 & 0.157 & $0.326 *$ & $0.313 *$ & 0.127 & 0.240 & $0.477 * *$ & 0.141 \\
\hline ASI & 0.128 & 0.166 & 0.154 & 0.188 & 0.092 & 0.240 & 0.266 & $0.35 I^{*}$ & 0.177 \\
\hline
\end{tabular}

Notes: $* P<0.05 ; * * P<0.01$. The boxes on the diagonal represent correlation coefficients between child and parent pain anxiety, pain catastrophizing and anxiety sensitivity at 48-72 hours, 6 months and 12 months after surgery.

Abbreviations: ASI, Anxiety Sensitivity Index; CASI, Childhood Anxiety Sensitivity Index; CPASS, Child Pain Anxiety Symptoms Scale; PASS, Pain Anxiety Symptoms Scale-20; PCS, Pain Catastrophizing Scale; PCS-C, Pain Catastrophizing Scale-Children.
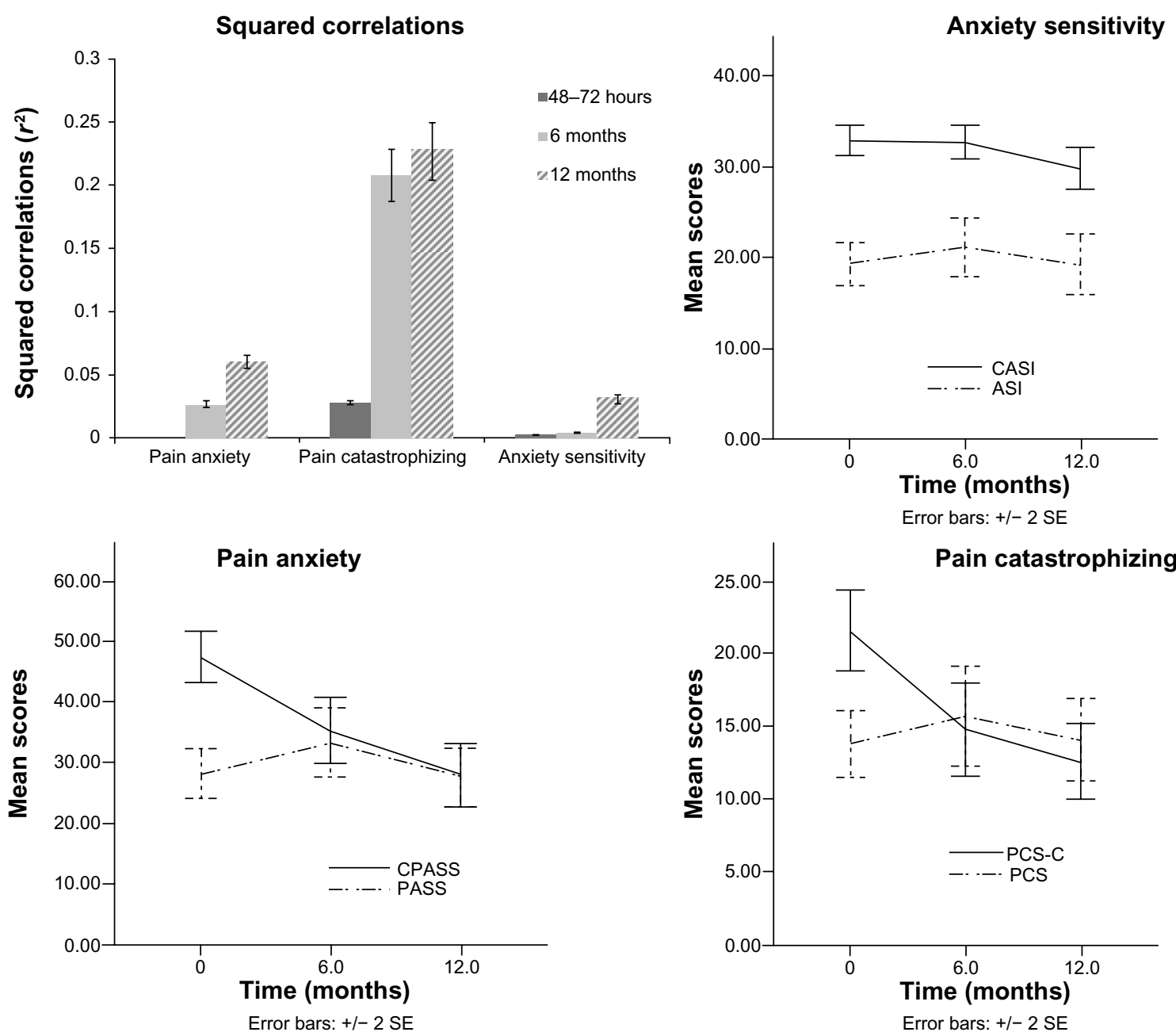

Figure 2 Squared correlation coefficients between child and parent pain anxiety, pain catastrophizing, and anxiety sensitivity $48-72$ hours, 6 months, and 12 months after surgery (upper left quadrant), and child and parent pain anxiety, pain catastrophizing, and anxiety sensitivity scores over the first year are shown in the other three quadrants.

Abbreviations: ASI, Anxiety Sensitivity Index; CASI, Childhood Anxiety Sensitivity Index; CPASS, Child Pain Anxiety Symptoms Scale; PASS, Pain Anxiety Symptoms Scale-20; PCS, Pain Catastrophizing Scale; PCS-C, Pain Catastrophizing Scale - Children; SE, standard error. 
Table 5 Agreement between child and parent on children's pain status 6 months and 12 months after surgery

6 months after surgery*

\begin{tabular}{|c|c|c|c|}
\hline & & \multicolumn{2}{|c|}{ Parent report of child's pain status } \\
\hline & & Moderate/severe CPSP (n) & No/mild CPSP (n) \\
\hline Child's self-reported & Moderate/severe CPSP (n) & 6 & 5 \\
\hline Pain status & No/mild CPSP (n) & 9 & 35 \\
\hline \multicolumn{4}{|c|}{12 months after surgery** } \\
\hline & & \multicolumn{2}{|c|}{ Parent report of child's pain status } \\
\hline & & Moderate/severe CPSP (n) & No/mild CPSP (n) \\
\hline Child's self-reported & Moderate/severe CPSP (n) & 5 & 6 \\
\hline Pain status & No/mild CPSP (n) & 10 & 29 \\
\hline
\end{tabular}

Notes: Moderate/severe CPSP is defined as reporting pain at the surgical site of pain intensity NRS $\geq 4$. *Kappa $=0.30, S E=0.14, t=2.27, P=0.023$. **Kappa $=0.18, S E=0.15$, $t=1.27, P=0.205$.

Abbreviations: CPSP, chronic postsurgical pain; SE, standard error.

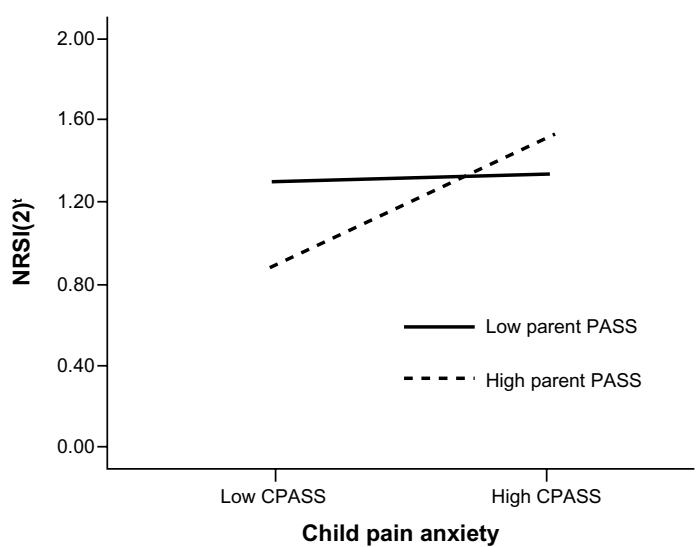

C

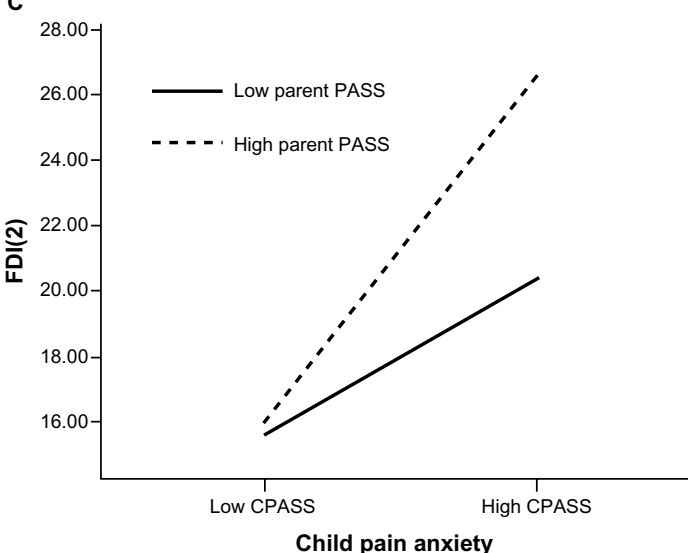

B

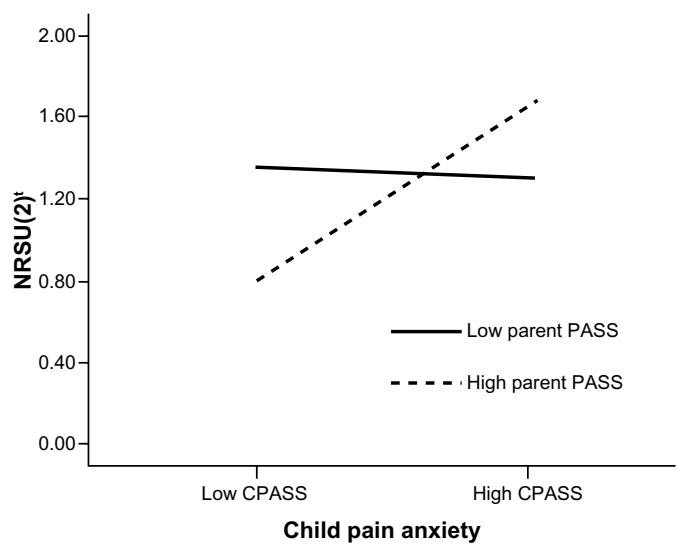

Figure 3 Interactions between parent and child pain anxiety 48-72 hours after surgery predict child pain intensity, pain unpleasantness, and functional disability 2 weeks after hospital discharge.

Notes: For pain intensity $(\mathbf{A})$ and pain unpleasantness (B), parents with low pain anxiety had children whose pain intensity and pain unpleasantness scores did not differ according to level of child pain anxiety. In contrast, among parents with high pain anxiety, child pain intensity and pain unpleasantness scores were significantly higher in children with high pain anxiety than in those with low pain anxiety. For functional disability (C), children with lower levels of pain anxiety reported similar levels of functional disability regardless of their parents' pain anxiety scores. Children with higher pain anxiety scores reported higher levels of functional disability if their parents also reported higher compared to lower pain anxiety $(\mathbf{C})$. The interaction between CPASS and PASS is based on continuous variables; the CPASS and PASS were dichotomized using median split for the purpose of illustrating the interaction.

Abbreviations: CPASS, Child Pain Anxiety Symptoms Scale measured 48-72 hours after surgery; FDI(2), Functional Disability Inventory measured 2 weeks after discharge from hospital; NRSI(2)t, Numeric Rating Scale for Pain Intensity transformed (square root transformation) measured 2 weeks after discharge from hospital; NRSU(2) ${ }^{\mathrm{t}}$, Numeric Rating Scale for Pain Unpleasantness transformed (square root transformation) measured 2 weeks after discharge from hospital; PASS, Pain Anxiety Symptoms Scale measured 48-72 hours after surgery. 
Given the correlational design of the present study, we do not know whether any of the risk factors we identified are causal. Nevertheless, the results of the present study raise the possibility that in the months following surgery, parents and children learn from each other's emotional responses to the pain experience and as such, over time, they exert a greater influence on each other's levels of pain catastrophizing.

Research has generally shown a weak relationship between a child's self-reported pain score and parent perceptions of their child's pain. ${ }^{59-62}$ In contrast, results from the present study indicated a significant relationship between child and parent acute pain ratings and a fair level of agreement between child and parent acute and chronic pain ratings up to 6 months after surgery. Children whose parent's scores indicated the child had clinically significant levels of acute postoperative pain rated their own pain intensity as higher compared to children whose parent's scores indicated the child had below clinically significant levels of pain. This finding is consistent with results showing that while parent and child ratings differed on the day of surgery and on the first postoperative day, this difference was no longer apparent by the second day after surgery. ${ }^{59}$

The results of the present study also show fair agreement between parents and children on the presence/absence of moderate/severe CPSP 6 months after surgery. Consistent with the existing literature, ${ }^{63,64}$ this agreement was not influenced by sex of the parent or child or by the child's age. The level of agreement between child and parent reports was no longer significant at 12 months after surgery. This indicates that parents and children are in greater agreement about the child's earlier CPSP status than later.

It is possible that other variables not examined in the present study may affect the agreement between child and parent pain reports including parent surgical history, child surgical complications, and child behavioral pain expression. It would be interesting for future studies to explore whether, and how, these variables influence child and parent agreement.

\section{Parent pain-related psychological factors associated with pediatric acute postsurgical pain}

The present results show that the interaction between parent and child pain anxiety 48-72 hours after surgery predicted pain intensity, pain unpleasantness, and functional disability levels 2 weeks after discharge from hospital. When parent pain anxiety is low, child pain levels 2 weeks later do not differ between children with high or low pain anxiety. Low parent pain anxiety may moderate the effect of child pain anxiety on pain intensity and unpleasantness levels. In contrast, higher levels of parent pain anxiety were associated with higher pain levels (intensity and unpleasantness) among children who also endorsed high levels of pain anxiety. High levels of parent pain anxiety, however, were associated with significantly lower pain among children with low pain anxiety. It is possible that in some as yet unknown way, high parent pain anxiety is protective against pain in children with low pain anxiety. Alternatively, this might reflect a subset of children who underreport pain and pain anxiety so as to protect their parents from excessive worry and distress over the child's pain.

Research has shown that parent and child postoperative anxiety are correlated,,$^{20}$ but the present results are the first to show that parent and child pain-specific anxiety interact to predict pain intensity and unpleasantness reports 2 weeks after discharge. The present results suggest that high levels of both child and parent pain anxiety shortly after surgery are risk factors for higher pain intensity, pain unpleasantness, and functional disability 2 weeks after discharge; however, we do not know if they are causal risk factors. It is possible that psychological interventions designed to reduce pain anxiety in parents whose children also have high pain anxiety would reduce child pain reports in the days and weeks after surgery.

Research on family and parent factors in pediatric pain has focused mainly on procedural pain or chronic pain and disability. Two primary theoretical models, the operant conditioning and family systems theories, have been used to examine parent-child pain dynamics. ${ }^{4}$ These models mainly focus on individual variables (eg, parental behaviors such as solicitousness and reinforcement, parenting style) or family variables (eg, family environment). As proposed in the integrative model of parent and family factors in pediatric chronic pain and associated disability ${ }^{4}$ and the pediatric fear-avoidance model of chronic pain, ${ }^{5}$ it is also important to consider dyadic variables; namely, interactions between parent-child painrelated factors. Results from the present study contribute to this literature by suggesting that parent and child pain-specific emotional responses interact to predict acute pain.

\section{Parent pain-related psychological predictors of pediatric CPSP}

Initial levels of parent pain catastrophizing predicted child pain intensity 12 months after surgery. Pain catastrophizing has been conceptualized as a way of communicating pain distress to others. ${ }^{65}$ As such, the parents may, through emotional and behavioral reactions, reinforce their child's pain 
behaviors and pain catastrophizing. ${ }^{56}$ It is possible that initial parental catastrophizing reinforces the child's pain behaviors, thoughts, and emotions (either through modeling or by directing attention to the pain) thereby placing the child at greater risk of developing CPSP 12 months after surgery. The finding that this relationship is absent at the 6 month follow-up and does not appear until 12 months suggests that there may be important differences in the development of CPSP (ie, from surgery to 6 months after surgery) versus the maintenance of CPSP (ie, from 6 months to 12 months after surgery) that are influencing this relationship. ${ }^{66,67}$ In this case, it may be that children are learning from their parents so that the effect of parent pain catastrophizing on child CPSP becomes apparent between 6 months and 12 months after surgery.

\section{Limitations}

There are limitations to the present study. First, for practical reasons, recruitment and initial assessment did not take place until 48-72 hours after surgery. Since we did not assess children or parents before surgery, a true baseline was not obtained. It would be important for future studies to examine the parentchild dyadic relationship at baseline in the absence of pain in order to better understand how it changes with time after surgery. Second, children in this study all underwent major surgical procedures and the results cannot be generalized to procedural pain (eg, injections) or minor surgical procedures. Third, significantly more mothers than fathers took part in this study making it difficult to examine sex differences between parents. Lastly, the FDI was inadvertently administered omitting the original " 2 " ("some trouble"), yielding possible item scores ranging from 0-3 instead of 0-4. As such, levels of functional disability in this study cannot be directly compared to other studies of pediatric postsurgical pain.

In conclusion, this study is the first to prospectively examine the relationship between parent and child pain-related psychological risk factors from acute pediatric pain to the development and maintenance of CPSP. Results indicate that while parent and child pain anxiety in the days after surgery interact to predict acute pain levels 2 weeks later, parent pain catastrophizing (48-72 hours after surgery) predicts the presence of CPSP 12 months after surgery. The results suggest the following hypothesis: as time from surgery progresses, parents exert an increasingly greater influence over the pain responding of their children so that by the 12 month mark, parent pain catastrophizing (measured in the days after surgery) is the main risk factor for the development of pediatric CPSP. A next step in this line of research would be to examine how different social and environmental factors, in addition to the parent-child dyad, influence pain outcomes in the short- and long-term. ${ }^{4}$

\section{Acknowledgments}

MGP is supported by a Canada Graduate Scholarship Doctoral Award from the Canadian Institutes of Health Research (CIHR). MGP is a trainee member of Pain in Child Health, a CIHR Strategic Training Fellow in Pain: Molecules to Community and a recipient of a Lillian-Wright Maternal-Child Health Scholarship from York University. JS is supported by a Ministry of Health and Long-term Care Career Scientist Award. JK is supported by a CIHR Canada Research Chair in Health Psychology at York University. Funds to conduct the study were provided by Dr Katz's Canada Research Chair.

\section{Disclosure}

The authors report no conflicts of interest in this work.

\section{References}

1. Melzack R, Wall PD. Pain mechanisms: a new theory. Science. 1965;150(3699):971-979.

2. Gatchel RJ. Perspectives on pain: a historical overview. In: Gatchel RJ, Turk DC, editors. Psychosocial Factors in Pain: Critical Perspectives. New York, NY: Guilford Press; 1999:3-17.

3. Gatchel RJ, Peng YB, Peters ML, Fuchs PN, Turk DC. The biopsychosocial approach to chronic pain: scientific advances and future directions. Psychol Bull. 2007;133(4):581-624.

4. Palermo TM, Chambers CT. Parent and family factors in pediatric chronic pain and disability: an integrative approach. Pain. 2005;119(1-3):1-4.

5. Asmundson GJ, Noel M, Petter M, Parkerson HA. Pediatric fearavoidance model of chronic pain: foundation, application and future directions. Pain Res Manag. 2012;17(6):397-405.

6. Wilson AC, Lewandowski AS, Palermo TM. Fear-avoidance beliefs and parental responses to pain in adolescents with chronic pain. Pain Res Manag. 2011;16(3):178-182.

7. Goubert L, Craig KD, Vervoort T, et al. Facing others in pain: the effects of empathy. Pain. 2005;118(3):285-288.

8. Jackson PL, Meltzoff AN, Decety J. How do we perceive the pain of others? A window into the neural processes involved in empathy. Neuroimage. 2005;24(3):771-779.

9. Goubert L, Eccleston C, Vervoort T, Jordan A, Crombez G. Parental catastrophizing about their child's pain. The parent version of the Pain Catastrophizing Scale (PCS-P): a preliminary validation. Pain. 2006;123(3):254-263.

10. Goubert L, Vervoort T, Sullivan MJ, Verhoeven K, Crombez G Parental emotional responses to their child's pain: the role of dispositional empathy and catastrophizing about their child's pain. $J$ Pain. 2008;9(3):272-279.

11. Guite JW, Logan DE, McCue R, Sherry DD, Rose JB. Parental beliefs and worries regarding adolescent chronic pain. Clin J Pain. 2009;25(3):223-232.

12. Chambers CT, Craig KD, Bennett SM. The impact of maternal behavior on children's pain experiences: an experimental analysis. $J$ Pediatr Psychol. 2002;27(3):293-301.

13. McMurtry CM, Chambers CT, McGrath PJ, Asp E. When "don't worry" communicates fear: children's perceptions of parental reassurance and distraction during a painful medical procedure. Pain. 2010;150(1):52-58. 
14. Walker LS, Williams SE, Smith CA, Garber J, Van Slyke DA, Lipani TA. Parent attention versus distraction: impact on symptom complaints by children with and without chronic functional abdominal pain. Pain. 2006; $122(1-2): 43-52$.

15. Logan DE, Scharff L. Relationships between family and parent characteristics and functional abilities in children with recurrent pain syndromes: an investigation of moderating effects on the pathway from pain to disability. J Pediatr Psychol. 2005;30(8):698-707.

16. Hopia H, Tomlinson PS, Paavilainen E, Astedt-Kurki P. Child in hospital: family experiences and expectations of how nurses can promote family health. J Clin Nurs. 2005;14(2):212-222.

17. Ribi K, Vollrath ME, Sennhauser FH, Gnehm HE, Landolt MA. Prediction of posttraumatic stress in fathers of children with chronic diseases or unintentional injuries: a six-months follow-up study. Child Adolesc Psychiatry Ment Health. 2007;1(1):16.

18. Meshkani ZS, Bavarian B. Parents' fear and distress during child inpatient care. Acta Med Iran. 2005;43(5):355-358.

19. Kain ZN, Mayes LC, O'Connor TZ, Cicchetti DV. Preoperative anxiety in children. Predictors and outcomes. Arch Pediatr Adolesc Med. 1996;150(12):1238-1245.

20. LaMontagne LL, Hepworth JT, Salisbury MH. Anxiety and postoperative pain in children who undergo major orthopaedic surgery. Appl Nurs Res. 2001;14(3):119-124.

21. McMurtry CM, McGrath PJ, Chambers CT. Reassurance can hurt: parental behavior and painful medical procedures. $J$ Pediatr. 2006; 148(4):560-561.

22. Connelly M, Anthony KK, Sarniak R, Bromberg MH, Gil KM, Schanberg LE. Parent pain responses as predictors of daily activities and mood in children with juvenile idiopathic arthritis: the utility of electronic diaries. J Pain Symptom Manage. 2010;39(3):579-590.

23. Pagé MG, Stinson J, Campbell F, Isaac L, Katz J. Identification of pain-related psychological risk factors for the development and maintenance of pediatric chronic post-surgical pain. J Pain Res. 2013;6: $167-180$.

24. McCracken LM, Gross RT. The role of pain-related anxiety in reduction in the outcome of multidisciplinary treatment for chronic low back pain: preliminary results. J Occup Rehabil. 1998;8(3):179-189.

25. McCracken LM, Zayfert C, Gross RT. The Pain Anxiety Symptoms Scale: development and validation of a scale to measure fear of pain. Pain. 1992;50(1):67-73.

26. Crombez G, Bijttebier P, Eccleston C, et al. The child version of the pain catastrophization scale (PCS-C): a preliminary validation. Pain. 2003;104(3):639-646.

27. Reiss S, Peterson RA, Gursky DM, McNally RJ. Anxiety sensitivity, anxiety frequency and the prediction of fearfulness. Behav Res Ther. 1986;24(1):1-8.

28. Kleiman V, Clarke H, Katz J. Sensitivity to pain traumatization: a higher-order factor underlying pain-related anxiety, pain catastrophizing and anxiety sensitivity among patients scheduled for major surgery. Pain Res Manag. 2011;16(3):169-177.

29. Martin AL, McGrath PA, Brown SC, Katz J. Anxiety sensitivity, fear of pain and pain-related disability in children and adolescents with chronic pain. Pain Res Manag. 2007;12(4):267-272.

30. Tsao JC, Allen LB, Evans S, Lu Q, Myers CD, Zeltzer LK. Anxiety sensitivity and catastrophizing: associations with pain and somatization in non-clinical children. J Health Psychol. 2009;14(8):1085-1094.

31. Vervoort T, Goubert L, Eccleston C, Bijttebier P, Crombez G. Catastrophic thinking about pain is independently associated with pain severity, disability, and somatic complaints in school children and children with chronic pain. J Pediatr Psychol. 2006;31(7): 674-683.

32. Turk DC. A diathesis-stress model of chronic pain and disability following traumatic injury. Pain Res Manag. 2002;7(1):9-19.

33. Martin AL, Halket E, Asmundson GJ, Flora DB, Katz J. Posttraumatic stress symptoms and the diathesis-stress model of chronic pain and disability in patients undergoing major surgery. Clin J Pain. 2010;26(6):518-527.
34. Vlaeyen JW, Kole-Snijders AM, Boeren RG, van Eek H. Fear of movement/(re)injury in chronic low back pain and its relation to behavioral performance. Pain. 1995;62(3):363-372.

35. Vlaeyen JW, Linton SJ. Fear-avoidance and its consequences in chronic musculoskeletal pain: a state of the art. Pain. 2000;85(3):317-332.

36. Pagé MG, Fuss S, Martin AL, Escobar EM, Katz J. Development and preliminary validation of the Child Pain Anxiety Symptoms Scale in a community sample. J Pediatr Psychol. 2010;35(10):1071-1082.

37. McCracken LM, Dhingra L. A short version of the Pain Anxiety Symptoms Scale (PASS-20): preliminary development and validity. Pain Res Manag. 2002;7(1):45-50.

38. Pagé MG, Campbell F, Isaac L, Stinson J, Martin-Pichora AL, Katz J. Reliability and validity of the Child Pain Anxiety Symptoms Scale (CPASS) in a clinical sample of children and adolescents with acute postsurgical pain. Pain. 2011;152(9):1958-1965.

39. Silverman WK, Fleisig W, Rabian B, Peterson RA. Childhood Anxiety Sensitivity Index. J Clin Child Psychol. 1991;20:162-168.

40. Reiss S, McNally RJ. Expectancy model of fear. In: Reiss S, Bootzin RR, editors. Theoretical Issues in Behavior Therapy. San Diego, CA: Academic Press; 1985:107-121.

41. Sullivan MJL, Bishop SR, Pivik J. The pain catastrophizing scale: development and validation. Psychol Assess. 1995;7(4):524-532.

42. Crombez G, Eccleston C, Baeyens F, Eelen P. When somatic information threatens, catastrophic thinking enhances attentional interference. Pain. 1998;75(2-3):187-198.

43. Walker LS, Greene JW. The functional disability inventory: measuring a neglected dimension of child health status. J Pediatr Psychol. 1991;16(1):39-58.

44. Kashikar-Zuck S, Vaught MH, Goldschneider KR, Graham TB, Miller JC. Depression, coping, and functional disability in juvenile fibromyalgia syndrome. J Pain. 2002;3(5):412-419.

45. Lynch AM, Kashikar-Zuck S, Goldschneider KR, Jones BA. Psychosocial risks for disability in children with chronic back pain. $J$ Pain. 2006;7(4):244-251.

46. Reid GJ, McGrath PJ, Lang BA. Parent-child interactions among children with juvenile fibromyalgia, arthritis and healthy controls. Pain. 2005;113(1-2):201-210.

47. Gidron Y, McGrath PJ, Goodday R. The physical and psychosocial predictors of adolescents' recovery from oral surgery. J Behav Med. 1995;18(4):385-399.

48. von Baeyer CL. Numeric rating scale for self-report of pain intensity in children and adolescents: recent progress and further questions. Eur $J$ Pain. 2009;13(10):1005-1007.

49. von Baeyer CL, Spagrud LJ, McCormick JC, Choo E, Neville K, Connelly MA. Three new datasets supporting use of the Numeric Rating Scale (NRS-11) for children's self-reports of pain intensity. Pain. 2009;143(3):223-227.

50. Vujanovic AA, Arrindell WA, Bernstein A, Norton PJ, Zvolensky MJ. Sixteen-item Anxiety Sensitivity Index: confirmatory factor analytic evidence, internal consistency, and construct validity in a young adult sample from The Netherlands. Assessment. 2007;14(2):129-143.

51. Chambers CT, Reid GJ, McGrath PJ, Finley GA. Development and preliminary validation of a postoperative pain measure for parents. Pain. 1996;68(2-3):307-313.

52. Pagé MG, Stinson J, Campbell F, Isaac L, Katz J. Pain-related psychological correlates of pediatric acute post-surgical pain. J Pain Res. 2012;5:547-558.

53. Altman DG. Practical Statistics for Medical Research. London, UK: Chapman and Hall; 1991.

54. Faul F, Erdfelder E, Buchner A, Lang AG. Statistical power analyses using $\mathrm{G}^{*}$ Power 3.1: tests for correlation and regression analyses. Behav Res Methods. 2009;41(4):1149-1160.

55. Martorella G, Côte J, Choinière M. Pain catastrophizing: a dimensional concept analysis. JAdv Nurs. 2008;63(4):417-426.

56. Sullivan MJ, Thorn B, Haythornthwaite JA, et al. Theoretical perspectives on the relation between catastrophizing and pain. Clin J Pain. 2001;17(1):52-64. 
57. Thorn BE, Clements KL, Ward LC, et al. Personality factors in the explanation of sex differences in pain catastrophizing and response to experimental pain. Clin J Pain. 2004;20(5):275-282.

58. Turner JA, Aaron LA. Pain-related catastrophizing: what is it? Clin J Pain. 2001;17(1):65-71.

59. Chambers CT, Reid GJ, Craig KD, McGrath PJ, Finley GA. Agreement between child and parent reports of pain. Clin J Pain. 1998;14(4): 336-342.

60. Kelly AM, Powell CV, Williams A. Parent visual analogue scale ratings of children's pain do not reliably reflect pain reported by child. Pediatr Emerg Care. 2002;18(3):159-162.

61. Bellman MH, Paley CE. Pain control in children. Parents underestimate children's pain. BMJ. 1993;307(6918):1563.

62. Goubert L, Vervoort T, Cano A, Crombez G. Catastrophizing about their children's pain is related to higher parent-child congruency in pain ratings: an experimental investigation. Eur J Pain. 2009;13(2):196-201.
63. Kröner-Herwig B, Morris L, Heinrich M, Gassmann J, Vath N. Agreement of parents and children on characteristics of pediatric headache, other pains, somatic symptoms, and depressive symptoms in an epidemiologic study. Clin J Pain. 2009;25(1):58-64.

64. Goodenough B, Thomas W, Champion GD, et al. Unravelling age effects and sex differences in needle pain: ratings of sensory intensity and unpleasantness of venipuncture pain by children and their parents. Pain. 1999;80(1-2):179-190.

65. Sullivan MJ, Adams H, Sullivan ME. Communicative dimensions of pain catastrophizing: social cueing effects on pain behaviour and coping. Pain. 2004;107(3):220-226

66. Katz J. One man's risk factor is another man's outcome: difference in risk factor profiles for chronic postsurgical pain maintenance vs transition. Pain. 2012;153(3):505-506

67. Dworkin RH. Which individuals with acute pain are most likely to develop chronic pain syndrome? J Pain. 1997;6(2):127-136.
Journal of Pain Research

\section{Publish your work in this journal}

The Journal of Pain Research is an international, peer-reviewed, open access, online journal that welcomes laboratory and clinical findings in the fields of pain research and the prevention and management of pain. Original research, reviews, symposium reports, hypothesis formation and commentaries are all considered for publication.

\section{Dovepress}

The manuscript management system is completely online and includes a very quick and fair peer-review system, which is all easy to use. Visit http://www.dovepress.com/testimonials.php to read real quotes from published authors. 